\title{
Treatment of dairy wastewater in UASB reactors inoculated with flocculent biomass
}

\author{
H Nadais ${ }^{1 *}$, I Capela ${ }^{1}$, L Arroja ${ }^{1}$ and A Duarte ${ }^{2}$ \\ ${ }^{1}$ Environment and Planning Department, University of Aveiro, 3810-193 Aveiro, Portugal \\ ${ }^{2}$ Chemistry Department, University of Aveiro, 3810-193 Aveiro, Portugal
}

\begin{abstract}
This work assesses the possibility of using flocculent sludge in UASB reactors applied to the treatment of dairy wastewater and studies the effect of hydraulic retention time $(6,8,12$ and $16 \mathrm{~h})$ on the performance of the reactors. The results show that the performance of flocculent sludge is similar to what has been reported in literature for granular sludge. It was observed that by raising the HRT from 6 to $12 \mathrm{~h}$ the performance of the system is improved concerning the maximum applicable load, the COD removal efficiency and methane production, but by raising the HRT from 12 to $16 \mathrm{~h}$ the differences are not meaningful. To attain soluble COD removals, VFA removals and protein mineralisation near $80 \%$ and fat removals above $60 \%$ it is necessary to operate the UASB reactors at an HRT of at least $12 \mathrm{~h}$. In addition to this the reactors must be operated at loads under $2.5 \mathrm{~g} \mathrm{COD} / \ell \cdot \mathrm{d}$ in order to attain a conversion to methane of the removed COD above $70 \%$.
\end{abstract}

Keywords: UASB, hydraulic retention time, optimum load, flocculent biomass, dairy wastewater

\section{Introduction}

The absence of granulation in UASB reactors used for the treatment of dairy wastewater has been considered as a major limitation to the application of this technology to this kind of complex substrates. According to Lettinga et al. (1998), the operation of UASB reactors does not need granular sludge and it is possible to use flocculent sludge with good settleability. It is known that in the case of the anaerobic degradation of dairy wastewater (DWW) the limiting step is the hydrolysis of particulate substrates (Pavlostatis and Giraldo-Gomez, 1991) or the degradation of the long-chain fatty acids, LCFA, to volatile fatty acids, VFA, (Hanaki et al., 1981). According to Yang and Anderson (1993) in the anaerobic degradation of DWW the bacterial population of fat hydrolysers and LCFA oxidisers should comprise as much as $60 \%$ of the total biomass in order that the granular sludge may be able to completely degrade the fat present in the wastewater.

According to the same authors it is possible that a biomass with the required ecological structure is unable to remain in granular form being selectively washed out from the reactors once it has been formed. Moreover, the results from Yang and Anderson (1993) show that the ecological population shift was rather slow with granular sludge. It is natural that flocculent sludge being predominantly acidogenic (Lettinga, 1996) will result in a better degradation of complex substrates, compared to granular sludge which is mainly methanogenic (Lettinga, 1996). Hwu (1997) verified that in expanded granular sludge bed (EGSB) reactors the bacteria that degrade LCFA to VFA were found in the fine biomass particles and not in granular aggregates. This might be an explanation for some results in the literature indicating a low degradation of milk fat in anaerobic reactors with granular sludge (Yang and Anderson, 1993; Petruy

* To whom all correspondence should be addressed.

욜 +351234370 200; fax: +351 234429 290;

e-mail: hadais@dao.ua.p

Received 16 August 2004; accepted in revised form 26 July 2005. and Lettinga, 1997). These findings led Hwu (1997) to operate granular sludge reactors with biomass recirculation, an HRT of $24 \mathrm{~h}$ and upflow velocities of $1 \mathrm{~m} / \mathrm{h}$, a set of flow conditions that are more typical of UASB reactors than of EGSB reactors. On the other hand UASB reactors inoculated with flocculent sludge bear higher solids content in the feed than the granular sludge reactors (Lettinga et al, 1998), and so the former is more adequate for the treatment of dairy wastewater. In full-scale DWW treatment plants generally a partial acidification takes place in the equalisation basin raising the solids content of the reactor feed.

The objective of this work was to study the application of UASB reactors inoculated with flocculent biomass for the degradation of dairy wastewater at mesophilic temperature. In order to study the influence of the hydraulic retention time (HRT) and the organic load on the reactor behaviour, UASB reactors were operated at HRTs of $6,8,12$ and $16 \mathrm{~h}$ with organic loads ranging between 1 and $8 \mathrm{~g} \mathrm{COD} / \ell \cdot \mathrm{d}$.

\section{Experimental}

For this study cylindrical UASB reactors were used with a height of $1.70 \mathrm{~m}$ and a working volume of $31.7 \ell$, built out of PVC and topped with three-phase separators as described by Fergala (1995). The reactors were kept at a temperature of $(35 \pm 1)^{\circ} \mathrm{C}$ in a climate room. Every hour the sludge bed was intermittently mixed with a mechanical agitator at $40 \mathrm{r} / \mathrm{min}$ for $10 \mathrm{~min}$, to prevent channelling and to improve the feed-biomass contact.

Initially the reactors were fed with wastewater from a dairy industry (COD 700 to $1200 \mathrm{mg} / \ell$; fats 75 to $150 \mathrm{mg} / \ell ; \mathrm{pH} 9.5$ to 11) supplemented with alkalinity and nutrients as in Gujer and Zendher (1983). From the third month onwards the feed was prepared by dilution of semi-skimmed milk with tap water and addition of alkalinity and nutrients. Table 1 presents a summary of the operating conditions. All routine chemical analyses were performed according to Standard Methods (1995). The VFAs were determined with a gas chromatograph Chrompack GC 438-s with an FID detector $\left(\mathrm{T}=250^{\circ} \mathrm{C}\right)$ equipped with a CP-Sil 


\begin{tabular}{|l|l|l|l|l|}
\hline \multicolumn{5}{|c|}{ TABLE 1 } \\
\hline Reactor & $\begin{array}{l}\text { HRT } \\
\text { (h) }\end{array}$ & $\begin{array}{l}\text { Upflow } \\
\text { velocity } \\
(\mathbf{m} / \mathbf{h})\end{array}$ & $\begin{array}{l}\text { Load } \\
(\mathbf{g} \text { COD/e-d) }\end{array}$ & $\begin{array}{l}\text { Feed COD } \\
(\mathbf{g} \text { COD/l) }\end{array}$ \\
\hline I & 6.2 & 0.27 & $0.5-7.0$ & $0.8-11.0$ \\
\hline II & 8.1 & 0.21 & $0.5-6.5$ & $1.5-17.6$ \\
\hline II & 12.1 & 0.14 & $1.5-6.5$ & $9.1-39.4$ \\
\hline IV & 15.8 & 0.11 & $1.5-7.5$ & $15.8-79.0$ \\
\hline
\end{tabular}

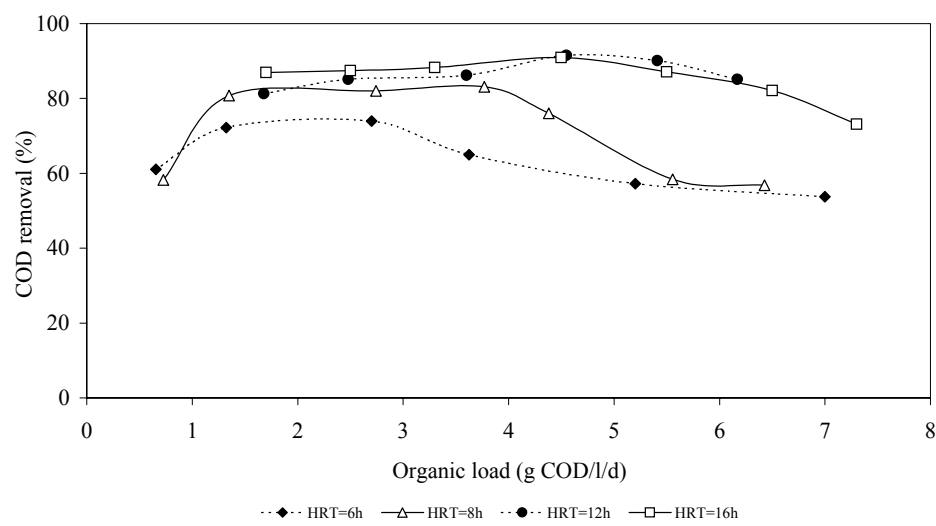

Figure 1

COD removal efficiencies as a function of the applied organic load for the different HRTs tested

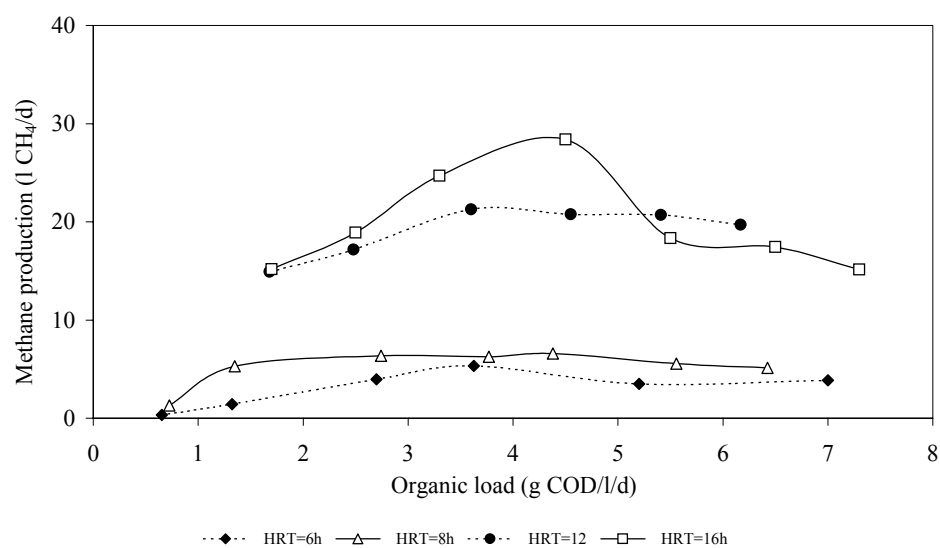

Figure 2

Methane production as a function of the applied organic load for the different HRTs tested

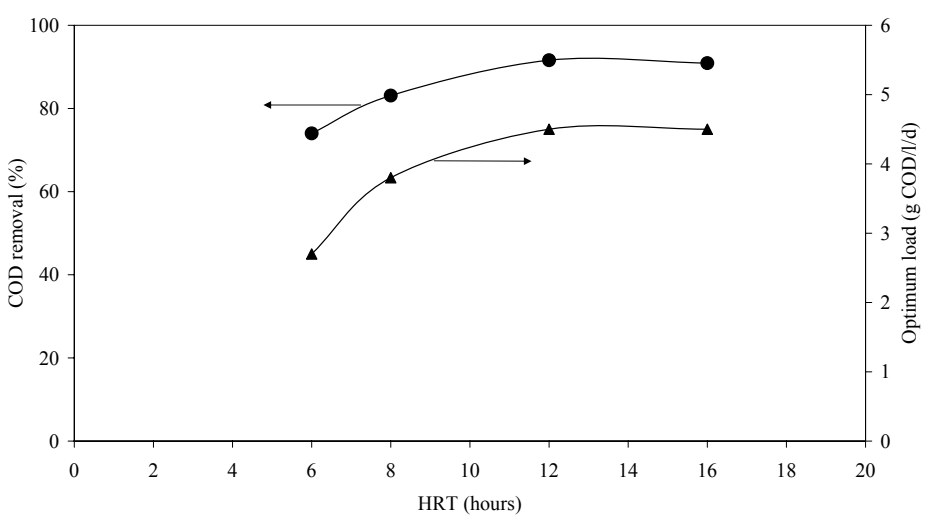

Figure 3

Maximum COD removal efficiency and optimum load attained for each HRT
19-CB $50 \mathrm{~m} \times 0.53 \mathrm{~mm}$ df $2 \mathrm{~mm},\left(\mathrm{~T}=80^{\circ} \mathrm{C}\right)$. The injection temperature was $225^{\circ} \mathrm{C}$ and helium was used as carrier gas at a flow of 1 to $5 \mathrm{ml} / \mathrm{min}$. The methane content in the biogas was analysed in a Chrompack GC 4385 gas chromatograph with a $\mathrm{TCD}\left(\mathrm{T}=180^{\circ} \mathrm{C}\right)$ equipped with a Carboplot P7 $25 \mathrm{~m} \times 0.53 \mathrm{~mm}$ df $25 \mathrm{~mm}\left(\mathrm{~T}=100^{\circ} \mathrm{C}\right)$. The injection temperature was $180^{\circ} \mathrm{C}$ and hydrogen was used a carrier gas with a pressure of $32 \mathrm{kPa}$.

The reactors were seeded with flocculent sludge from an urban wastewater treatment plant previously adapted to dairy substrate in the laboratory for a 2-month period $(\mathrm{VSS}=23 \mathrm{~g} / \ell ; \mathrm{TSS}=27.4 \mathrm{~g} / \ell ; \mathrm{COD}=19$ $\mathrm{g} / \ell ; \mathrm{pH}=7.5)$. Each reactor was seeded with $20 \ell$ of sludge. The methanogenic activity of the sludge was 0.26 $\mathrm{gCH}_{4}-\mathrm{COD} / \mathrm{gVSS}$.d determined with sodium acetate with a concentration of $0.6 \mathrm{~g} \mathrm{COD} / \mathrm{g} \mathrm{SSV}$ at $(35 \pm 1)^{\circ} \mathrm{C}$. The sludge content in the reactors was determined regularly by calculation of the volatile suspended solids (VSS) profile along the reactor height. The filtered COD samples were obtained with Whatman GFC (CODpf) and with membrane OE67 from Schleicher \& Schuel (CODmf).

\section{Results and discussion}

Figures 1 and 2 present the COD removal efficiencies and the methane production resulting from the operation of four UASB reactors with different HRT. The COD removal was calculated from the total COD of the feed and the paper filtered COD (CODpf) of the effluent.

It is clear that for the lower HRTs (6 and $8 \mathrm{~h})$ the COD removal efficiencies and especially the methane productions are inferior to those obtained with the higher HRTs (12 and $16 \mathrm{~h}$ ). Yet for all the HRTs tested the COD removal efficiency and the methane production present a somewhat sharp decrease corresponding to a certain load ( 3 to $6 \mathrm{~g} \mathrm{COD} / \ell \cdot \mathrm{d}$ ) which was lower for the smaller HRT. Some authors have previously reported a sharp decrease in the COD removal efficiency for loads above 2-4 g COD/ $\ell \cdot d$ in the operation of sludge bed anaerobic reactors fed with dairy effluents (Bull et al., 1982; Shin and Paik, 1990; Morgan et al., 1991).

Considering that the optimum load corresponds to the maximum COD removal efficiency, the results of this work (Figs. 1 and 3) show that the raise in the HRT from 6 to $8 \mathrm{~h}$ or from 8 to $12 \mathrm{~h}$ results in a significant raise of the optimum load, but a similar improvement is not observed for a raise in the HRT from 12 to $16 \mathrm{~h}$. An influence of the HRT was also observed in relation to the methane production, although the most striking influence of the HRT was observed between 8 and $12 \mathrm{~h}$ HRT, as can be seen in Fig. 2.

Figure 4 presents the methanisation of the removed COD for the several HRTs studied. For a $6 \mathrm{~h}$ HRT the per cent conversion is approximately constant and very low $(<20 \%)$. For the $8 \mathrm{~h}$ HRT the methanisation of the removed COD has a maximum $(25 \%$ to $40 \%)$ for the lower loads, dropping to a value of about $15 \%$ for the higher loads. For the reactors operated with an HRT of 12 and $16 \mathrm{~h}$ the methanisation is higher, from $80 \%$ to $85 \%$ with the lower loads to $20 \%$ to $30 \%$ with the higher loads. It can be seen from Figs. 3 and 4 that for all the 


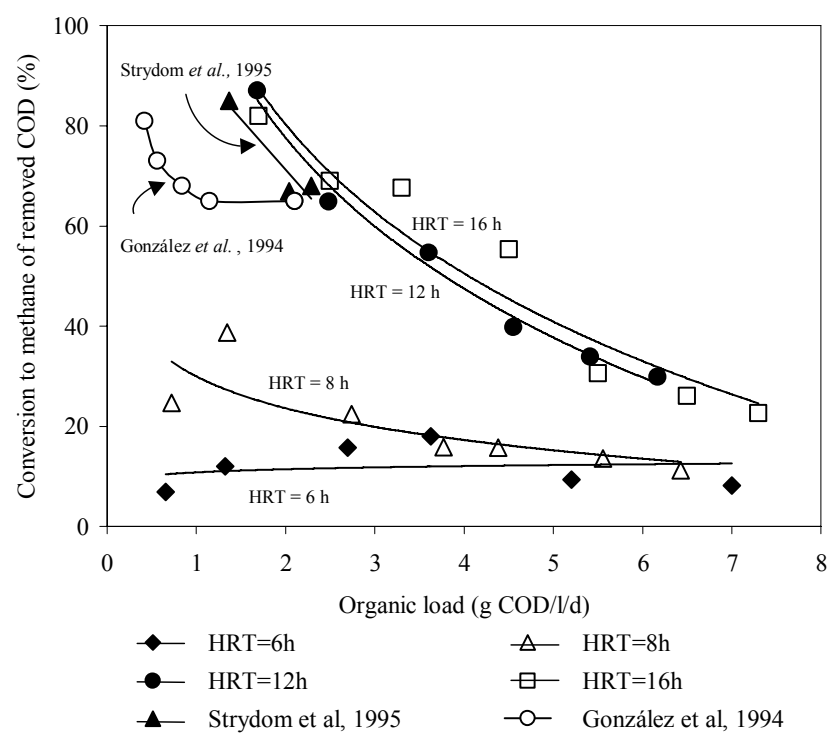

Figure 4

Conversion to methane of the removed $C O D$ as a function of the applied load

Note: González et al. 1994, values calculated from published data; Strydom et al. 1995, direct data

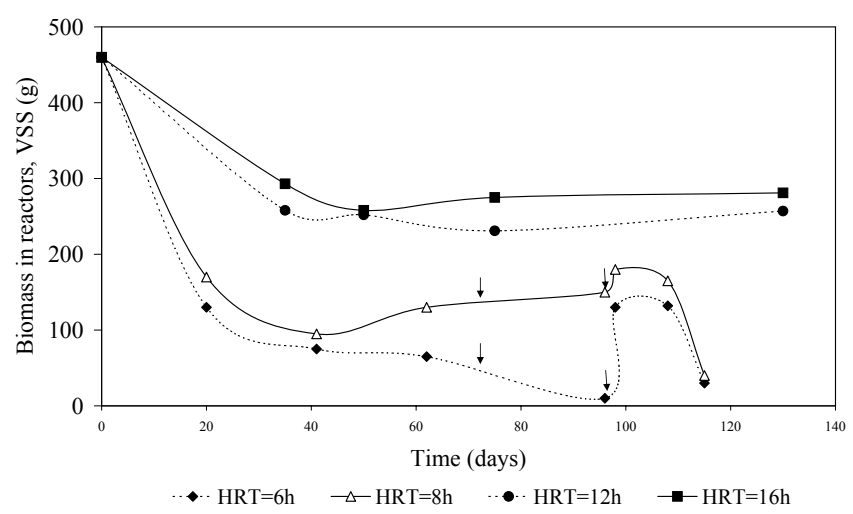

Figure 5

Biomass concentration in the reactors. The arrows indicate re-inoculation.

HRTs tested the maximum value of the conversion to methane of the removed COD does not correspond to the optimum load (load at which the maximum COD removal efficiency is obtained) but to a quite lower load. As an example, with the $12 \mathrm{~h}$ HRT reactor the optimum load was $4.5 \mathrm{~g} \mathrm{COD} / \ell \cdot \mathrm{d}$, with a removal efficiency of about $90 \%$, yet the conversion to methane obtained with the same load was only $45 \%$, which implies heavy accumulation of organic matter in the sludge bed.

Analyses of the data published in the literature for anaerobic reactors treating dairy wastewater confirm the discrepancy between COD removal and COD methanisation supporting the idea of heavy accumulation of organic matter in the sludge bed. Motta Marques et al. (1990) verified that in fluidised bed reactors (HRT 10 to $120 \mathrm{~h}$, loads 0.5 to $12 \mathrm{~g} \mathrm{COD} / \ell \cdot \mathrm{d}$ ) the conversion to methane of the removed COD was $40 \%$ to $55 \%$, whilst the COD removal reached $70 \%$ to $93 \%$. In that work the substrate accumulation was confirmed by the formation of organic layers inside the reactors that impaired the bed expansion for the lower flows. In a study with horizontal anaerobic filters treating dairy wastewater Córdoba et al. (1984) obtained conversions to meth- ane of the removed COD under $50 \%$ when the load surpassed $3 \mathrm{~g} \mathrm{COD} / \ell \cdot \mathrm{d}$ while the COD removal was kept between $85 \%$ and $90 \%$.

The results obtained in this work also show a similar tendency to what was reported by Strydom et al. (1995) who verified that for a UASB-hybrid reactor treating dairy wastewater and operated with an HRT of $4.5 \mathrm{~d}$ the conversion to methane of the removed COD dropped from about $85 \%$ for a load of 1.37 $\mathrm{g} \operatorname{COD} / \ell \cdot \mathrm{d}$ to about $67 \%$ to $68 \%$ for loads of 2.04 to $2.29 \mathrm{~g}$ $\mathrm{COD} / \ell \cdot d$. González et al. (1994) observed that in UASB reactors treating dairy wastewater the conversion to methane of the removed COD decreased gradually from about $80 \%$ to about $65 \%$ for HRTs of between 0.5 and $1.5 \mathrm{~d}$ and for COD removal efficiencies of $93.4 \%$ to $95.4 \%$. For comparison the results from González et al. (1994) and Strydom et al. (1995) are presented in Fig. 4 together with the results obtained in this work for all the HRTs tested.

The authors referred to above (Bull et al., 1982; Córdoba et al., 1984; Motta Marques et al., 1990; Shin and Paik, 1990; Morgan et al., 1991; González et al., 1994; Strydom et al., 1995) justified the observed reactor failure by the accumulation of organic matter inside the reactors and the loss of active biomass by sludge wash-out.

In this work the build-up of organic matter (especially fats) in the reactor sludge bed resulted in biomass flotation and accumulation in the upper section of the three-phase separator, forming a layer that can reach a depth of 50 to $100 \mathrm{~mm}$. Biomass and a significant amount of whitish organic matter oily to the touch formed this sludge layer. It was observed that the sludge layer remained agglomerated on the top of the reactor and that an interruption of the reactor operation during periods of more than one day would lead to the sedimentation of this layer. Due to the formation of this sludge layer on the top of the three-phase separator the operation of the reactors also included the daily cleaning of the biogas lines in order to avoid clogging by the fatty matter and biomass entrained with the ascending biogas.

The results presented here, in relation to the effect of the HRT on the behaviour of the UASB reactors used for the treatment of DWW, indicate that a raise of the HRT from 6 to 12 to $16 \mathrm{~h}$ will benefit the system in terms of COD removal efficiency and methanisation of the substrate removed. In what concerns the substrate degradation, the raising of the HRT may have two opposing effects in the UASB performance, namely it may raise the contact time between the biomass and the substrate, allowing for a better degradation of the organic matter (Backman et al., 1946), while, on the other hand, the lowering of the upflow velocity may diminish the mixing inside the reactor and for that reason impair the contact between the substrate and the biomass. Within the range of volumetric flows tested in this work, the raising of the upflow velocity will cause more biomass entrainment, heavier formation of sludge layers on the top of the reactor and consequently a higher biomass wash-out. The results presented in Fig. 5 confirm that the loss of biomass was higher with the lower HRTs. In all the reactors a significant loss of biomass was observed in the first $40 \mathrm{~d}$ of operation (corresponding to organic loads of less than $5 \mathrm{~g} \mathrm{COD} / \ell \cdot \mathrm{d})$. This initial biomass wash-out was heavier in the reactors operated with 6 and $8 \mathrm{~h}$ HRT $(85 \%$ and $80 \%$ of biomass wash-out, respectively), compared to the reactors operated over 12 and $16 \mathrm{~h}$ HRT (45\% and 35\% biomass wash-out, respectively). From the $50^{\text {th }}$ day onwards the biomass content in the reactors with 12 and $16 \mathrm{~h}$ HRT stabilised. In the reactor operated at $8 \mathrm{~h}$ HRT there was a slight improvement in the biomass content between the 40th and the 60th days whilst with the $6 \mathrm{~h}$ HRT the stabilisation of the biomass content was 


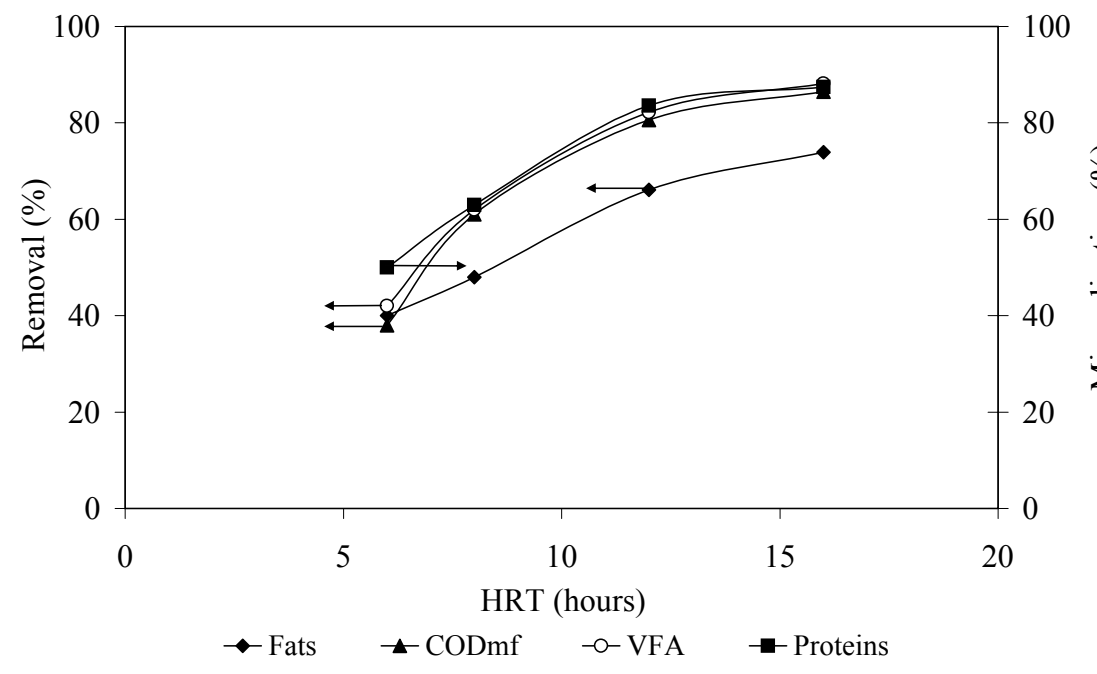

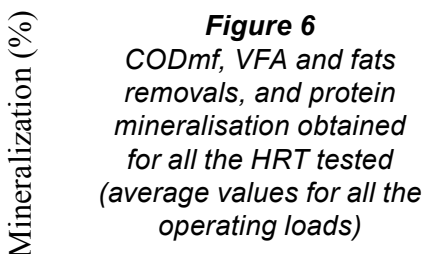

verified only for very low biomass values inside the reactor.

Since it was observed that the reactors operated with 6 and 8 $\mathrm{h}$ HRT had a low biomass concentration, these reactors were reinoculated with flocculent sludge from a municipal wastewater treatment plant. The re-inoculations took place at day 72 and 96 , as indicated by the arrows in Fig.5, and it was observed that the first re-inoculation had different effects in the two reactors. In the reactor with $6 \mathrm{~h}$ HRT the re-inoculation had a detrimental effect in the sludge bed leading to an almost complete loss of reactor biomass, whilst for the $8 \mathrm{~h}$ HRT reactor no significant effect was noted in terms of biomass content, that is $25 \mathrm{~d}$ after the re-inoculation the biomass concentration was similar to the situation before the re-inoculation. A second re-inoculation was made to assess in detail the effect of the addition of non-adapted biomass to the reactors. The amount of added biomass was calculated so as to obtain the same biomass concentration in both reactors ( 6 and $8 \mathrm{~h}$ HRT). The analysis of the biomass content at days 98, 108 and 115, confirmed the detrimental effect of the re-inoculation with non-adapted biomass, which was clearly observed in both reactors. Probably the added biomass clogged to the biomass already present inside the reactors and due to its lack of adaptation to the substrate it was easily entrained, leading to a heavy biomass wash-out from the reactors within only $20 \mathrm{~d}$ of operation. Apparently, the extension of the negative effects of the re-inoculation does not depend on the HRT and the load imposed upon the reactors.

These results suggest that the re-inoculation with nonadapted sludge should not be considered as a strategy to improve the behaviour of UASB reactors used for the treatment of dairy wastewater, since the effects are detrimental to the sludge bed.

Figure 6 presents the average results of the removal of soluble COD (CODmf), VFA and fats removal, and also the efficiency of protein mineralisation, for all the HRTs tested. In what concerns the CODmf and VFA removals and protein mineralisation, the most significant effect of a raise in the HRT was observed between 6 and $8 \mathrm{~h}$, but for the fats removal, the highest improvement was detected for the raise from 8 to $12 \mathrm{~h}$.

The results obtained in this work confirm other results from the literature (Bull et al., 1982; Córdoba et al., 1984; Motta Marques et al., 1990; Shin and Paik, 1990; Morgan et al., 1991; González et al., 1994; Strydom et al., 1995; Petruy, 1999) according to which it is not possible to attain the load values typical of anaerobic high load reactors in sludge bed reactors fed with dairy wastewater. The analysis of the data obtained suggests that the main reason for reactor failure with this kind of wastewater

can be ascribed to the sludge bed acting as a filter (Verstraete and Vandevivere, 1999) resulting in acceptable COD removals without a corresponding biological degradation fast enough to avoid organic matter accumulation in the sludge bed. This interpretation is in accordance with what has been previously reported about the mechanisms of COD removal in anaerobic reactors for the treatment of DWW (Petruy, 1999; Nadais et al., 2001; Nadais et al., 2003).

\section{Conclusions}

- It is possible to operate UASB reactors with flocculent sludge for the treatment of dairy wastewater with similar results to what is found in the literature for granular sludge.

- For HRTs between $6 \mathrm{~h}$ and $16 \mathrm{~h}$ a raise from $6 \mathrm{~h}$ to $12 \mathrm{~h}$ results in a clear improvement of reactor performance, but when the HRT is raised from $12 \mathrm{~h}$ to $16 \mathrm{~h}$ the improvement is minimal. An HRT of $12 \mathrm{~h}$ or higher is necessary to attain both soluble COD and VFA removals and protein mineralisation near $80 \%$ and fat removals above $60 \%$. In addition to operation at the optimum HRT the applied load must not exceed $2.5 \mathrm{~g} \mathrm{COD} / \ell \cdot \mathrm{d}$ in order to attain COD conversions to methane above $70 \%$.

- The low percentage of conversion to methane of the removed COD indicates a significant accumulation of organic matter in the sludge bed for all the HRT tested, suggesting the need of an alternative operating mode, since the raise in HRT above $12 \mathrm{~h}$ does not improve the system behaviour.

\section{Acknowledgements}

This work was done under a Ph.D. grant from Program PRAXIS XXI (J.N.I.C.T. - Portugal).

\section{References}

BACKMAN R, BLANC F and O'SHAUGHNESSY J (1946) The treatment of dairy wastewater by the anaerobic up-flow packed bed reactor. Proc. Purdue Industrial Waste Conference 361-372.

BULL M, STERRITT R and LESTER J (1982) The effect of organic loading on the performance of anaerobic fluidised beds treating high strength wastewaters. Trans. IChemE 60 373-376.

CÓRDOBA P, RIERA F and SINERIZ F (1984) Treatment of dairy industry wastewater with an anaerobic filter. Biotechnol. Lett. 16 (11) $753-758$.

FERGALA M (1995) The Anaerobic Treatment of Complex Wastewa- 
ter. Ph.D. Thesis. Van Hall Institute, Groningen, The Netherlands.

GONZÁLEZ J, VALDÉS P, NIEVES, G and GUERRERO, B (1994) Aplicación de la digestión anaerobia a los residuales de industrias lácteas. Revista Internacional de Contaminacion Ambiental 10 (1) $37-41$.

GUJER W and ZENDER A (1983) Conversion processes in anaerobic digestion. Water Sci. Technol. 15 127-167.

HANAKI K, MATSUO T and NAGASE M (1981) Mechanisms of inhibition caused by long chain fatty acids in anaerobic digestion process. Biotechnol. Bioeng. 23 1591-1560.

HWU C-S (1997) Enhancing Anaerobic Treatment of Wastewaters Containing Oleic Acid. Ph.D Thesis. Agricultural University of Wageningen, Wageningen, The Netherlands.

LETTINGA G (1996) Sustainable integrated biological wastewater treatment. Water Sci. Technol. 33 (3) 85-98.

LETTINGA G, HULSHOFF POL L and ZEEMAN G (1998) Lecture notes on Biological Wastewater Treatment - Part I: Anaerobic Wastewater Treatment. Agricultural University of Wageningen, Sub-Department of Environmental Technology, Wageningen, The Netherlands.

MORGAN J, EVISON L and FORSTER C (1991) Changes in the microbial ecology in anaerobic digesters treating ice cream wastewater during start-up. Water Res. 25 (6) 639-653.

MOTTA MARQUES D, CAYLESS S and LESTER J (1990) Process aiders for start-up of anaerobic fluidised bed systems. Environ. Technol. 11 1093-1105.

NADAIS H, CAPELA I. ARROJA L and DUARTE A (2003) Biosorption of milk substrates onto anaerobic flocculent and granular sludge. Biotechnol. Prog. 19 1053-1055.

NADAIS H, CAPELA I, ARROJA L and DUARTE A. (2001) Kinetic analysis of anaerobic degradation of dairy wastewater. Proc. 9th World Congress on Anaerobic Digestion 2001, Antwerp. Part I 203-208.

PAVLOSTATHIS S and GIRALDO-GOMEZ E (1991) Kinetics of anaerobic treatment. Water Sci. Technol. 24 (8) 35-59.

PETRUY R and LETTINGA G (1997) Digestion of a milk-fat emulsion. Bioresour. Technol. 61 141-149.

PETRUY R (1999) Anaerobic Treatment of Protein, Lipid and Carbohydrate Containing Wastewaters Using the EGSB Technology. $\mathrm{Ph}$.D. Thesis. Agricultural University of Wageningen, Wageningen, The Netherlands.

SHIN H and PAIK B (1990) Improved performance of UASB reactors by operating alternatives. Biotechnol. Lett. 22 (6) 469-474.

STANDARD METHODS (1995) Standard Methods for the Examination of Water and Wastewater (19 ${ }^{\text {th }}$ edn.) American Public Health Association/American Water Works Association/Water Environment Federation. Washington DC, USA.

STRYDOM J, MOSTERT J and BRITZ T (1995) Anaerobic treatment of a synthetic dairy effluent using a hybrid digester. Water $S A \mathbf{2 1}$ (2) $125-130$

VERSTRAETE W and VANDEVIVERE P (1999) New and broader applications of anaerobic digestion. Crit. Rev. Environ. Sci. Technol. 28 (2) 151-173.

YANG J and ANDERSON G (1993) Effects of wastewater composition on stability of UASB. J. Environ. Eng. 119 (5) 958-977. 
